This is a pre-publication version of the paper published in Journal of Language \& Social Psychology (2015), 34 (4), 464-470. DOI: 10.1177/0261927X15587017.

\title{
Responding to -isms
}

Susan A. Speer ${ }^{\text {i }}$

\footnotetext{
${ }^{\mathrm{i}}$ University of Manchester, Manchester, UK
}

\section{Corresponding Author:}

Dr Susan A. Speer, School of Psychological Sciences, Coupland Building 1, The University of Manchester, Oxford Road, Manchester M13 9PL

UK

Email: $\underline{\text { susan.speer@manchester.ac.uk }}$ 


\begin{abstract}
I discuss the contribution of the papers to existing literatures, and their implications for (i) our understanding of the analytic tractability of -isms, and (ii) managing and challenging -isms.
\end{abstract}

\title{
Keywords
}

Conversation analysis, prejudice, talk-in-interaction, racism, sexism, heterosexism 
I first came to the topic of -isms - "a term used to refer to phenomena including sexism, racism, heterosexism, and the like" (Whitehead \& Stokoe, this issue) - as a doctoral student in the 1990s. Schegloff's (1997) influential paper, Whose text? Whose context? had just been published, and feminist, critical and discursive psychology colleagues were abuzz with discussion of its implications for our research. Put simply, Schegloff encouraged critically oriented researchers not to assume in advance of an analysis that gender, differential statuses, or unequal power relations are relevant to, and can explain, what is taking place within interaction. Rather, we might begin by exploring what is "demonstrably relevant" and oriented to by the participants themselves.

While some considered this approach "unbearably limiting” (Kitzinger 2000, p. 171), I took up the methodological challenge that Schegloff posed (see also contributions in Speer \& Stokoe 2011). In my work on a range of -isms (Goodman \& Speer 2007, Speer, 2002, 2005, Speer \& Potter 2000), I aimed to see just how far an approach which begins with an analysis of members' perspectives, and "interaction internal" evidence alone, could take us in understanding phenomena that are often thought to require "interaction external" explanations.

Operationalizing -isms as utterances in which speakers appear to justify inequality of some kind, I asked: Is prejudice analytically tractable? Can we find participants orienting to their own talk, or that of others, as sexist or heterosexist? What interactional resources do participants use to produce and sustain prejudiced accounts and bolster their arguments against attack? How do conversationalists deal with, pre-empt and foreclose counterarguments and challenges?

This work examined both the composition and "sequential organisation" of prejudicial utterances (Speer 2002, p. 370). However, since it was principally concerned to challenge the dominant social cognitive approach that reduced prejudice to the kinds of decontextualized 
statements found in attitude scales, Whitehead and Stokoe (this issue) rightly point out that previous work on -isms, including my own, "paid less attention to how -isms can be responded to by the recipients for whom they are produced". The papers in this special issue bring together an international group of researchers from psychology and communication studies to address this gap in the literature head on.

Using data from diverse everyday and institutional settings, the contributors draw on a range of analytic techniques including CA (Whitehead, Stokoe), feminist CA (Weatherall), membership categorization analysis (Robles), and a combination of discourse analysis and CA (Romaniuk), to examine "interactional sequences in which-isms are interactionally produced and responded to" (Whitehead \& Stokoe). In doing so, they significantly advance our understanding of “how participants 'do' (anti)racism, (anti)sexism, and so on, in situated interactions" (Whitehead \& Stokoe, this issue).

In this commentary I draw out some broader implications of the papers for (i) our understanding of the analytic tractability of $-i s m s$, and (ii) everyday and institutional approaches to managing and challenging-isms.

\section{On the analytic tractability of -isms}

The authors agree that since producers and recipients of -isms rarely orient towards, or characterise them explicitly as such (e.g., in the form "I'm a racist" (Whitehead, Excerpt 3) or "r((h)acist) ass" (Robles, Excerpt 2), that they are hard to "pin down" (Robles) for both analysts and participants. As Stokoe notes, this lack of explicit orientations and references to -isms "goes to the heart of debates in conversation analysis about the empirical warrants for particular kinds of observations, and the designed defeasibility of social action."

The authors deal with the problem of gaining analytic tractability on-isms in different ways: Whitehead contributes to research on "everyday antiracism" by examining "features of 
preference organization in disaffiliative responses to possibly racist actions" in South African radio call-in shows. Adopting an approach consistent with Schegloff's (1996b, pp. 116-117) characterization of an object of analysis as "a possible X", Whitehead uses the term "possibly racist" (rather than simply "racist") to describe the actions he analyses, since "although they may be based on a range of common features that make them recognizable (and thus analyzable) as such, [they] are subject to (re)negotiation by participants in the moment-bymoment unfolding of interactions."

The utterances that Whitehead identifies as possibly racist:

(i) have been described as racist in prior talk (e.g., "Africa isn't the only third world country that benefited from colonialism" [Excerpt 1]);

(ii) make links between groups of people and negative attributes (e.g., "nonwhite South Africans" and a propensity to violence against women [Excerpt 2]).

(iii) are explicitly oriented to by the speaker as racist (e.g., "Yes I'm a racist." [Excerpt 3]).

Like Whitehead, Stokoe is concerned not to pre-define-isms in a decontextualized way. She uses the notion of possible -isms to examine mediation sequences in which one or more parties say "something possibly racist, sexist, or otherwise prejudiced, in the course of making, warranting and defending against complaints about other neighbours", "and the responses they generate from professional mediators who are trained to be impartial".

Explicitly operationalising the features that make talk "hearable, and analysable, as a possible -ism", Stokoe notes that the caller's claim “They're A:sian families who seem to 'ave no control over their children" (lines 10-11, Excerpt 1) is a possible-ism because:

(i) it is preceded by a disclaimer ('I shoul:ldn't sa:y this.=but I'm go:in' to say because it's perfectly true:"). 
(ii) it makes relevant "something about a family as the basis for generalization; the complainability of the families who have no control is ramped up with 'Asian', attaching an attribute to a category as an explanation".

Other features that characterise possible -isms in Stokoe's extracts include:

(iii) lexical or grammatical components that are routinely used in reports of racial abuse (e.g., "Stick y’pampas gra:ss back in the $\uparrow$ pampas" [Excerpt 6] echoes “fuck off back to your own country").

(iv) speech perturbations including "the hesitation, pause, in-breath and puncheddelivery of the category 'Indian"” in "Next door nei:ghbour. (0.7) Um:: (0.2) .hhhhh is:: >Indian.<" (Excerpt 7).

(v) the explicit orientation to (and denial of) racism ("An' that's not ra:cist" [Excerpt 7]).

Stokoe's last excerpt, which she uses with her CARM (Conversation Analytic Roleplay Method) workshop participants, neatly demonstrates the value of adopting a CA approach that treats utterances as only "possible" -isms that can "turn out not to be". Focussing on the caller's utterance: “And she's West Indian so she'll have reggae parties an' stuff like that", Stokoe notes that the mediator responds with silence, which is disaffiliative. Moreover, as her workshop participants point out, "making a category relevant ('she's West Indian') and tying it to a particular behaviour ('so...') might be racist” (see also Excerpts 1 and 7). It is only later, as the interaction unfolds, that the caller reports he is a victim of racial abuse, accounting for it on the basis that he is Asian and his wife is West Indian. This exposes the mediator's (and the workshop participants') misplaced (prejudicial) assumptions about the caller's category membership and that it is he who is racist.

For Robles "possibly-racist discourse" is talk in which "participants explicitly name a racial category, associate it with a negatively-assessed activity" (e.g., "she's black (.) so you 
know she's gunna buy (.) like (stupid) shit" [Excerpt 1]), "and they or their interlocutors orient to that as problematic".

Finally, Weatherall and Romaniuk offer a more politicised approach to the problem of the analytic tractability of -isms. Instead of focussing on "-isms in action", as they happen in real time, Romaniuk examines "meta-sexist talk" in "U.S. media discussions regarding Hillary Rodham Clinton's failed bid for the U.S. Democratic nomination in 2007-2008” “where sexism was explicitly topicalized". Here, participants' understandings of "what counts" as (a valid claim of) sexism/a possible -ism, becomes the analytic topic.

Instead of using the notion of a "possible-ism", Weatherall examines "how documented aspects of sexist language actually unfold in social interaction'. These “documented aspects of sexist language" include:

"the derogatory use of female reference terms" (e.g., "old moaning wife" [Excerpt 3]).

(ii) gender exclusive language: Extracts 'show speakers' displayed orientation to being gender inclusive.' (e.g., 'he's go:t viability or she: (.) has got viability:' [Excerpt 4]).

The majority of Weatherall's extracts contain, through observable repairs, "or repair like practices" speakers' orientations to sexism. However, she suggests that "in Extract 3 old moaning wife is analysed as sexist when there is no evidence the participants are treating it that way" and that this runs "counter to a pure conversation analytic approach where the methodology dictates observations of members' displayed concerns are made, for example by the next-turn proof procedure".

I want to suggest that Weatherall's approach is in fact consistent with CA methodology. Indeed, using the next turn proof procedure as the sole source of validation of one's analytic claims cannot account for instances where the participants displayed 
understanding constitutes a "misunderstanding", or where a turn may prompt a particular next action but that action does not materialise (Schegloff, 1996a, p. 173: n6). As the contributors demonstrate, both of these things (misunderstanding and lack of uptake) may be rife with isms.

Additionally, members themselves do not have the benefit of access to "uptake" as a resource in deciding whether or not someone is being racist/sexist/homophobic. As Schegloff notes, inexplicitness and indexicality are "omnipresent" in interaction and "in the nature of the case, requires 'solving' by hearers" (1996a, p.209). It is for this reason that an additional way in which CA validates analytic claims is through an examination of compositional features of the actions themselves, which may have an "objective import" on formal grounds (Schegloff, 1996a, p.173, n6).

By examining these features in examples where the analyst does have interaction internal evidence in the form of members' orientations or uptakes that the parties understood the prior utterance or conduct, as "possibly doing" an -ism (Schegloff, 1996a, p.172) and providing an account "of what about the production of that talk/conduct provided for its recognisability as such an action" (Schegloff 1996a: 173), the analyst (and the parties to the interaction) can begin to identify a "possible instance" of an action such as racism/sexism/heterosexism on occasions where there is no such interaction internal evidence. Importantly, they can do this independent of "whether or not it was so understood by its recipient on any particular occasion" (Schegloff, 1996a, p.173, emphasis in original).

I have already begun to draw out, above, some of the compositional features of utterances that the contributors to this special issue identify as possible-isms. In order to provide an empirically grounded account of the social action of "producing an -ism" it may pay analytic dividends for future work to describe the full range of practices that constitute possible-isms in the way Schegloff describes, following the procedure outlined above. 


\section{Implications for managing and challenging -isms?}

I want to end by drawing out some of the implications of the papers for the everyday and institutional management of -isms. Robles notes that "communication is proffered as the solution to a variety of social problems". However, a fine grained analysis of interaction reveals a mismatch between formal advice about how to respond to -isms, and what happens and is effective in practice. In particular, a primary focus on the "obligation" and "moral imperative to address racism" using a direct approach in which speakers convey "disapproval and question speakers' reasoning" (Robles), leads to recommendations that are "at odds with other considerations in everyday interaction, including progressivity, relational, and face demands" (Robles). These considerations mitigate against a direct approach and affect (i) the way speakers produce -isms in the first place, as well as (ii) the way people "notice" and respond to -isms. Therefore, an awareness of such factors is essential to any effective prejudice reduction strategy.

In terms of the production of -isms, the contributors demonstrate convincingly that prejudicial discourse is "dispreferred" (Stokoe, Whitehead), "perhaps partly because it is seen as a product of a racist [sexist/heterosexist] person" (Robles). Therefore, potential -isms are “often delicately introduced" (Robles) and managed in ways that show speakers' "orientations to a (relatively contemporary) set of norms proscribing open expressions of" prejudice (Whitehead). As Stokoe notes, “'Real' -isms are designed to be withdrawablefrom" and members "build turns that are defeasible; that is, they are possibly and accountably not-isms but 'mere description', or something else." These strategies can work to avoid or discredit accusations of prejudice, making it hard for speakers to address and challenge possible-isms (Robles). 
In terms of responding to -isms: on the one hand, since overt disagreeing and sanctioning responses are disafilliative, they represent a threat to solidarity and the progressivity of the interaction and are dispreferred (Whitehead). On the other hand, "agreeing or affiliating with" a possible -ism, or "failing to directly challenge it" is also dispreferred, in that it risks placing the participant in a morally compromising position, and "being seen as complicit with the action" (Whitehead). Therefore, as Whitehead convincingly demonstrates, responding to -isms and successfully challenging prejudice involves managing these "cross-cutting preferences".

In addition to the cross-cutting preference issues that Whitehead identifies, Stokoe highlights some of the institutional barriers to challenging -isms. In the mediation setting, explicit challenges in which mediators admonish speakers who have produced them, can generate turbulence and misalignment and lead callers to refuse to mediate - outcomes that clearly conflict with institutional goals as well as the institutionally inscribed mediator impartiality. By contrast, when mediators implicitly resist -isms, by "sequentially deleting them using reformulations" they effectively manage a range of interactional concerns and may keep mediation "on course".

Robles and Weatherall demonstrate how aspects of the organization of repair can be used to respond to racism and sexism respectively: Robles shows that extreme case reformulations (ECRFs) which involve "echoing extreme versions of the problematic utterance [back to the speaker] to provide opportunities for repair work on inferable associations between membership categories and category-bound activities" (e.g., "a:(h)ll $t(h)$ ey drink i(h)s be(h)er (0.5) the morni::ng=" [Excerpt 4]) are a particularly effective resource for addressing "hearably racist talk". Although Robles notes that the "teasing and non-literal performance" aspect of the practice could be deemed problematic from a critical 
perspective, because it avoids "taking a serious issue seriously", ECRFs are effective precisely because they allow speakers to repair the possible -ism without explicit challenge.

Finally, Romaniuk's analysis of meta-sexist talk lends further support to the argument that direct accusations of prejudice are dispreferred. Romaniuk shows that explicit, post-hoc claims of sexism, are responded to by media interviewers with antagonistic and acquiescent responses that both serve to undermine the validity and legitimacy of the complaints.

Taken together, the studies show that, contrary to much standard communication advice, successfully challenging an -ism in real life interaction is not straightforward. Rather, sophisticated prejudice reduction strategies require awareness, and the careful balancing of, competing interactional demands, and training that is nuanced and contextualised. Indeed, sometimes, the most effective way to manage -isms may be via indirect or subtle strategies (e.g., silence, other markers of dispreference, and even humour) that may on the surface appear complicit with the -ism (by virtue of failing to challenge it explicitly), but which create slots where-isms can be acknowledged, repaired and/or backed away from, in a way that prevents interactional breakdown.

What appears crucial when debating how best to respond to possible -isms, is to consider, in light of the apparent functional purpose of the talk, "do the ends (e.g., keeping a mediation session on course and retaining clients, avoiding disharmony) justify the means (e.g., failing to directly challenge an -ism, or challenging it implicitly rather than explicitly). Trainees and researchers may benefit from looking at the kinds of real-life interactions analysed here to discuss precisely these issues. Indeed, using CA to expose members' practices to scrutiny is itself subversive and provides the basis for "application with integrity" (Stokoe).

\section{Declaration of Conflicting Interests}


The author declared no potential conflicts of interests with respect to the authorship and/or publication of this article.

\section{Funding}

The author received no financial support for the research and/or authorship of this article.

\section{References}

Goodman, S., \& Speer, S.A. (2007). Category use in the construction of asylum seekers. Critical Discourse Studies, 4, 165-185.

Kitzinger, C. (2000). Doing feminist conversation analysis. Feminism and Psychology, 10, 163-193.

Schegloff, E. A. (1996a). Confirming allusions: Towards an empirical account of action. American Journal of Sociology, 104, 161-216.

Schegloff, E. A. (1996b). Turn organization: One intersection of grammar and interaction. In E. Ochs, S. A. Thompson \& E. A. Schegloff (Eds.), Interaction and grammar (pp. 52133). Cambridge, UK: Cambridge University Press.

Schegloff, E. A. (1997). Whose text? Whose context? Discourse and Society, 8, 165-87.

Speer, S. A. (2002). Sexist talk: Gender categories, participants' orientations and irony. Journal of Sociolinguistics, 6, 347-377.

Speer, S. A. (2005). Gender talk: Feminism, discourse and conversation analysis. London, UK: Routledge.

Speer, S. A., \& Potter, J. (2000). The management of heterosexist talk: Conversational resources and prejudiced claims. Discourse and Society, 11, 543-572.

Speer, S. A., \& Stokoe, E. (Eds.) (2011). Conversation and gender. Cambridge, UK: Cambridge University Press. 


\section{Author Biography}

Susan A Speer is Senior Lecturer in Psychology in the School of Psychological Sciences at the University of Manchester, UK. She has published discursive and conversation analytic work on clinical communication, gender identity and prejudice, and research methodology in action. She is the author of Gender Talk: Feminism, Discourse and Conversation Analysis (2005) and co-editor (with Elizabeth Stokoe) of Conversation and Gender (2011). 